\title{
COMPARATIVE EVALUATION OF ANTI INFLAMMATORY EFFECT OF BROMELAIN-TRYPSIN COMBINATION VERSUS DICLOFENAC SODIUM AFTER SURGICAL REMOVAL OF MANDIBULAR THIRD MOLAR TEETH
}

\author{
*Dr. A.S.M. Ariful Islam ${ }^{1}$, Dr.Mohammad Asifur Rahman ${ }^{2}$, Dr. Shakhawat Hossain ${ }^{3}$, Dr. Quazi Billur Rahman ${ }^{4}$
}

\section{AFFILIATION:}

1. Dr. A.S.M. Ariful Islam BDS, MS(OMS), Medical Officer, Department of Oral \& Maxillofacial Surgery, Dhaka Dental College \& Hospital, Dhaka, Bangladesh

2. Dr.Mohammad Asifur Rahman, BDS, MS(OMS), Assistant Professor

Department of Oral \& Maxillofacial Surgery, Dhaka Dental College \& Hospital, Dhaka, Bangladesh

3. Dr. Shakhawat Hossain, BDS, MS(OMS),

Assistant Professor,

Department of Oral and Maxillofacial Surgery,

Bangabandhu Sheikh Mujib Medical University, Dhaka, Bangladesh

4. Dr. Quazi Billur Rahman, MD, Ph. D,

Professor \& Chairman,

Department of Oral and Maxillofacial Surgery,

Bangabandhu Sheikh Mujib Medical University, Dhaka, Bangladesh

\section{Article info.}

Received: 10 November, 2019

Accepted: 11 January 2020

Volume: 10, Issue-1 April, 2020

DOI: https://doi.org/10.3329/updcj.v10i1.46687

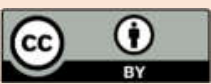

(c) Authors retain copyright and grant the journal right of first publication with the work simultaneously licensed under Creative Commons Attribution License CC - BY 4.0 that allows others to share the work with an acknowledgment of the work's authorship and initial publication in this journal.

https://creativecommons.org/licenses/by/4.0/

Publisher: Update Dental College, Dhaka, Bangladesh

Web: www.updatedentalcollege.edu.bd

E-mail: updcj@hotmail.com

\author{
* Corresponding Author \\ Dr. A.S.M. Ariful Islam BDS, MS(OMS), \\ Medical Officer, Department of Oral \& Maxillofacial Surgery, \\ Dhaka Dental College \& Hospital, Dhaka, Bangladesh \\ E-mail:dr.arif.omfs@gmail.com \\ Cell: +8801717672225
}

\section{Citation}

Islam MA, Rahman MA, Hossain S, Rahman Q B. Comparative evaluation of anti inflammatory effect of bromelain-trypsin combination versus diclofenac sodium after surgical removal of mandibular third molar teeth.UpDCJ.2020 Apr;10(1):1620. Available from: DOI: https://doi.org/10.3329/updcj.v10i1.46687

\begin{abstract}
Aim: The focus of the education was to assess the success between localanesthetic infiltration injection and inferior alveolar nerve block anesthesia in extraction of Chronic periodontitis mandibular posterior teeth.

Methods: 100 patients aged between 13 and 73 years who attended the Department of Dental surgery, BIRDEM General Hospital for extraction of advance periodontitis of mandibular molars were included in this study. For the infiltration anesthetic technique, patient's approval was taken. The patients were equally divided into two groups. Group (1) received $0.6 \mathrm{ml}$ out of $1.8 \mathrm{ml}$ of $2 \%$ lidocaine with $1: 80000$ adrenaline injection bucally and the same amount infiltration lingually opposite the intended tooth. Group (2) received $1.5 \mathrm{ml}$ out of $1.8 \mathrm{ml}$ of $2 \%$ lidocaine with $1: 80000$ and the remaining $0.3 \mathrm{ml}$ was injected for long buccal nerve anesthesia.

Results: In this Study we found 88\% patients were pain free and Group-2 94\% patients were pain free During extraction of Advance periodontitis of mandibular molars. P-value was 0.138 and it was not $<0.05$. So it was not significant. On the other side 103 patients out of 113 were pain free in male and 79 patients out of 87 were pain free in female and 6 patients out of 87 were feeling pain during tooth extraction of advance periodontitis of mandibular molars. P-value was 0.138 and it was not $<0.05$. So it was not significant.

Conclusion: Infiltration anesthesia for non-vital mandibular molars is effective as a substitute for inferior alveolar block technique.
\end{abstract}

\section{KEYWORDS: Bromelain-trypsin, Diclofenac sodium, Surgical} extraction.

\section{INTRODUCTION}

Removal of impacted mandibular third molars is one of the most common surgical procedures routinely taken in the oral and maxillofacial surgery clinic. Usually post-operative recovery of patient takes several days and patient is advised bed rest and absence from work. This post-operative course is dominated by pain, swelling, trismus and dysphagia which reflect inflammatory tissue reactions. Such complications, in turn, influence the patient's quality of life in the Immediate postoperative period.1

Therefore, various methods have been attempted through the years to minimize the post-operative sequelae. The most common reason for people seeking the advice of health professional is that they are in sort of post-operative painafter third molar surgery. In general pain is symptom of some form of dysfunction and subsequent inflammatory process in the body.Non-steroidal anti-inflammatory drugs (NSAIDs) have often been prescribed to reduce inflammatory complications, especially pain, caused by third molar extraction. ${ }^{2,3}$ However, the side-effects associated with the use of NSAIDs are numerous, primarily those related to gastrointestinal, hematologic and renal disorders and the propensity to cause skin and mucosal reactions. ${ }^{4}$ Hence, a natural, effective and safe remedy that lacks undesired side effects would offer a welcome alternative treatment of sequelae after third molar 
surgery. The most common post operated complication after the extraction of an impacted wisdom tooth are direct consequence of the inflammatory response to the surgical procedure. And include pain, inflammation and difficulty opening mouth. 5,6 Generally this response is controlled with the surgical technique. 7,8 And mainly with pharmacological anti-inflammatory measure. 9

Many drugs are available that help to reduce inflammation and relieve pain after third molar surgery. They act by interfering with the body's natural inflammatory response mechanism. However their chronic use may lead to side effects.Over the past few years research suggest role for more natural and safe alternatives for the management of pain and inflammation after 3 rd molar surgery. Recent clinical studies show that the Bromelain-Trypsin combination to be a very potent and safe in reliving edema, inflammation and promoting wound healing. The anti-inflammatory effect of protelytic enzymes has been proved by several clinical studies.10 The individual therapeutic role of these natural substances was established long back in 1960 , but in recent years further clinical studies were done to prove this role more substantially and now there is sufficient evidence that the combination of Bromelain-Trypsin has significant implication in alleviate edema and inflammation.10 A recent study on the cardiovascular safety of NSAIDs has highlighted further evidence that Diclofenac Sodium is associated with cardiovascular risks thatare higher than the other non-selective NSAIDs and similar to the selective COX-2 inhibitors. ${ }^{11}$ Thus their frequent use is not recommended. Another group of drugs used in severe inflammatory conditions are steroids that contribute to even more severe and serious adverse effects on long-term use. Clinicians and medical researchers worldwide are in general agreement that pharmacologic pain treatment is unsatisfactory and the irrational use of NSAIDs in such conditions is adding the agony of the patients. Thus new drugs can be the choice to replace NSAIDs to treat pain. Newer natural and safer alternatives identified in recent past are Bromelain and Trypsin. Their combination to treat inflammatory diseases is coming out with promising results.

\section{MATERIALS AND METHOD}

The study was conducted among the 50 patients in the OPD, Oral and Maxillofacial Surgery Department and was approved by institutional review board of Bangabandhu Sheikh Mujib Medical University with impacted (Buccaly placed, Class I ramus, Class A depth, Pell \& Gregory classification of impacted lower third molar teeth) mandibular third molar that was divided in two groups in which 25 patients were in each group. Group A (25) patients were prescribed Bromeline - Trypsin combination as 1 Tab. 8 hourly for 3 days than 1 Tab. 12 hourly from $4^{\text {th }}$ to $7^{\text {th }}$ days and group (B) 25 patients were prescribed Diclofenac Sodium as below dose. 1 Tab. 12 hourly after meal for 7 days. After the completion of the procedure, a standardized structured data collection sheet was used to collect necessary information of the study subject. Pain was evaluated after 3, 7 and 15 days following surgery with the VAS (Visual Analog Scale) scale. ${ }^{12}$ Swelling was recorded using scale from $0=$ none, $1=$ Intra oral swelling, $2=$ Intra and extra oral swelling, and $3=$ Obliteration of the angle of mandible after 3,7 and 15 days following surgery. Maximal interincisal opening was measured in $\mathrm{mm}$ after 3,7 and 15 days following surgery. 13

\section{RESULTS}

In total 50 patient with impacted (Buccaly placed, class I ramus, Class A depth, Pell \& Gregory classification) mandibular third molar that was randomly divided in two groups (Group: A and $B$ ) in which 25 patients were in each group. This study was carried out to compare the effect of oral BromelainTrypsin combination versus oral Diclofenac Sodium on pain, swelling, maximum mouth opening in two groups of patients after surgical removal of impacted lower third molars. Follow up of cases were done $3^{\text {rd }}, 7^{\text {th }}, 15^{\text {th }}$ days post operatively.

Figure 1: Distribution of the study patients by age $(n=50)$

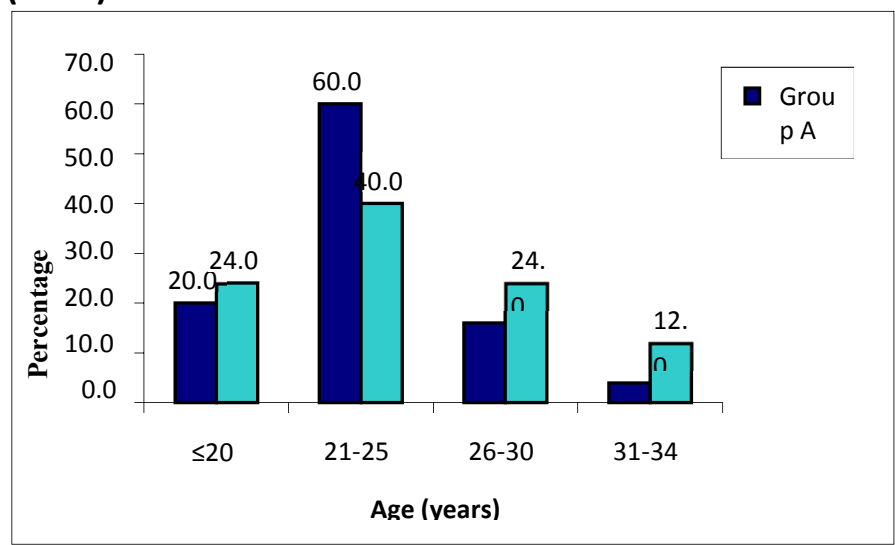

Group A: Prescribed Bromeline-Trypsin Group B: Prescribed Diclofenac Sodium

It was observed that almost two third (60.0\%) patients in group $A$ and $10(40.0 \%)$ patients in group $B$ were belonged to age $21-25$ years. The mean age was found $23.5 \pm 3.8$ years in group $A$ and $24.4 \pm 4.3$ years in group $B$.

Figure 2: Distribution of the study patients by gender $(n=50)$

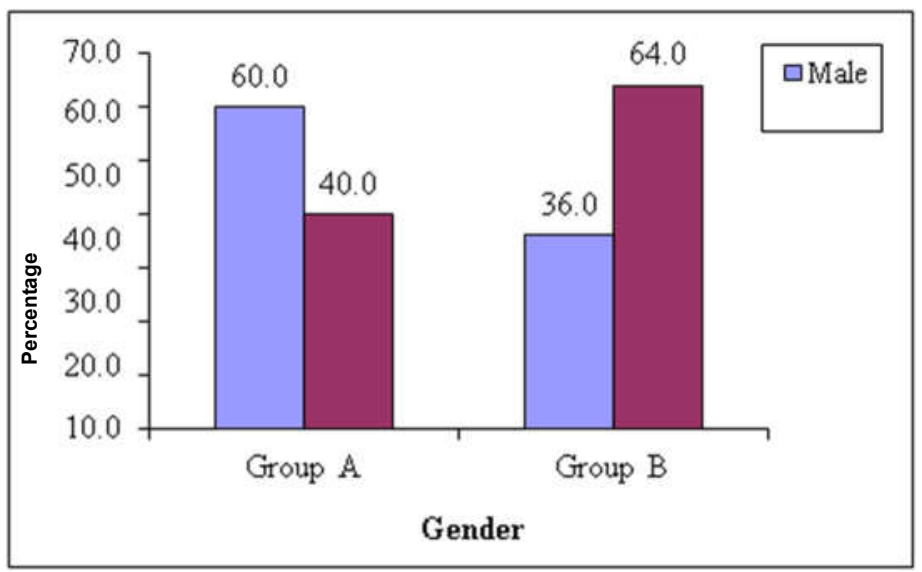

it was observed that 10 (40.0\%) patients were female in group A and 16(64.0\%) patients in group B. Figure 3: Distribution of the study patients by preoperative chief complaints $(n=50)$ 


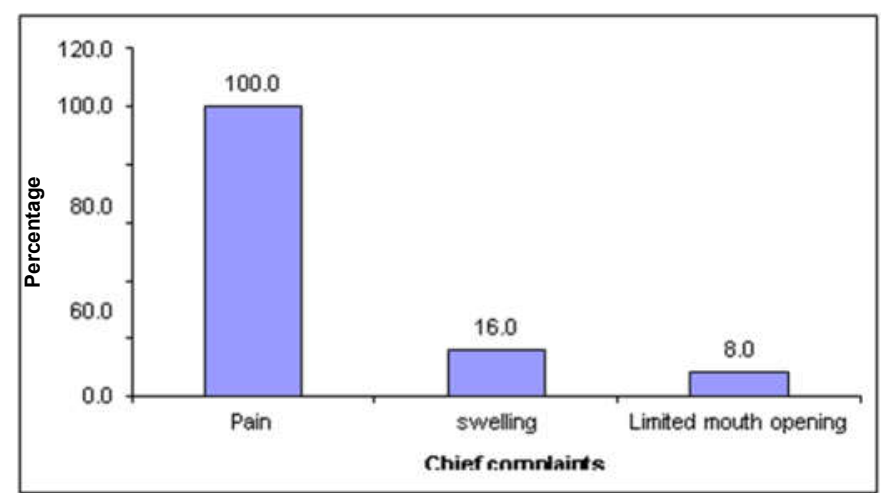

In preoperative chief complaints all patients had pain 50(100.0\%). Among them swelling was present $8(16.0 \%)$ patients and limited mouth opening was $4(8.0 \%)$ patients.

Table I : Distribution of the study patients by mouth opening in post - operative evaluation period $(n=50)$.

Table I : Distribution of the study patients by mouth opening in post - operative evaluation period $(n=50)$.

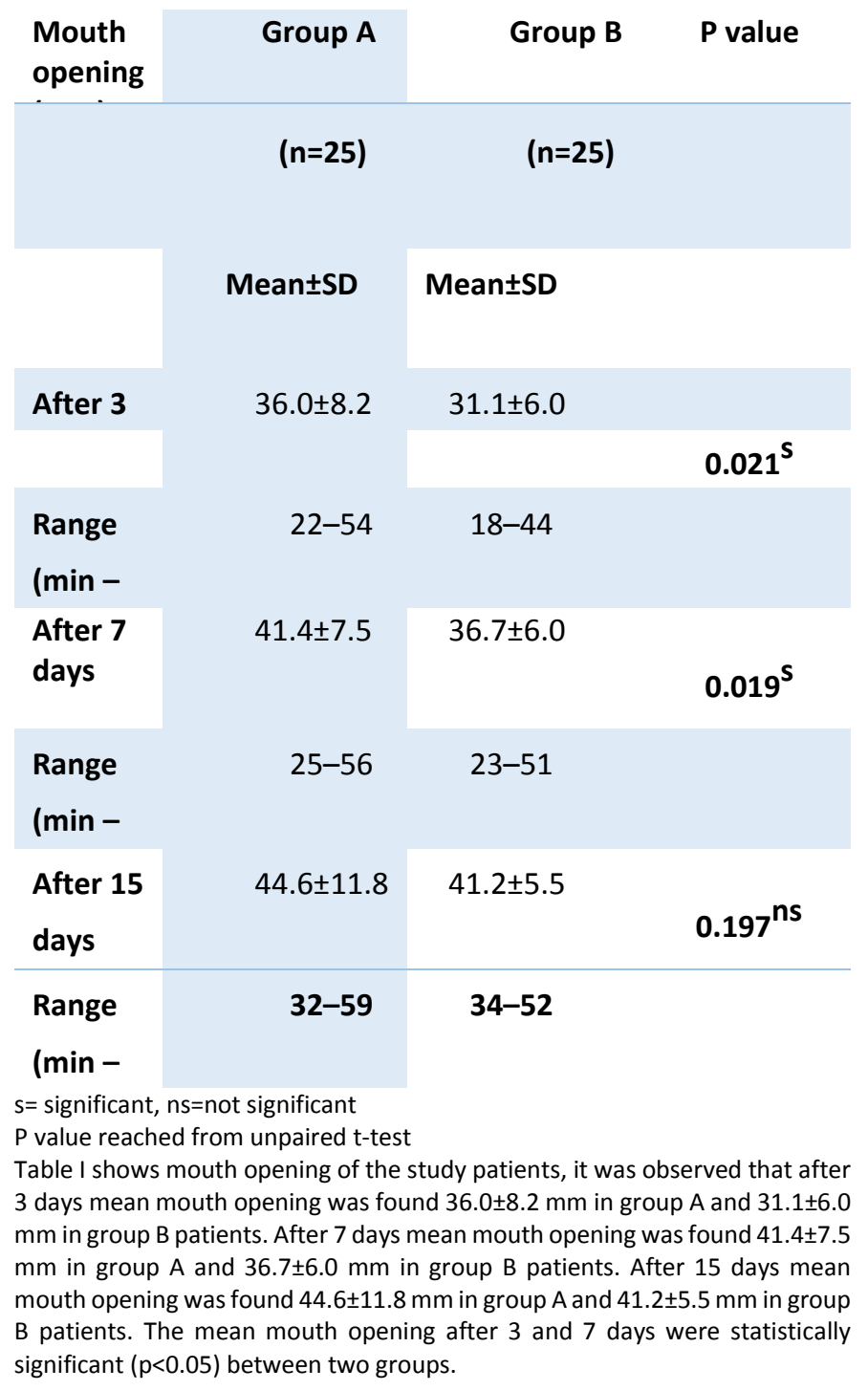

Table II: Distribution of the study patients by swelling in postoperative evaluation period $(n=50)$.

\begin{tabular}{|c|c|c|c|c|c|}
\hline \multirow[t]{3}{*}{ Swelling } & \multirow{2}{*}{\multicolumn{2}{|c|}{$\begin{array}{l}\text { Group A } \\
(n=25)\end{array}$}} & \multirow{2}{*}{\multicolumn{2}{|c|}{$\begin{array}{l}\text { Group B } \\
(n=25)\end{array}$}} & \multirow{3}{*}{$\begin{array}{l}P \\
\text { value }\end{array}$} \\
\hline & & & & & \\
\hline & $\mathbf{n}$ & $\%$ & $\mathbf{n}$ & $\%$ & \\
\hline \multicolumn{6}{|l|}{ After 3 days } \\
\hline None & 1 & 4.0 & 2 & 8.0 & \\
\hline Intra oral swelling & 13 & 52.0 & 4 & 16.0 & \multirow{2}{*}{$0.030^{S}$} \\
\hline Intra and extra oral swelling & 9 & 36.0 & 11 & 44.0 & \\
\hline Obliteration of the angle of mandible & 2 & 8.0 & 8 & 32.0 & \\
\hline \multicolumn{6}{|l|}{ After 7 days } \\
\hline None & 8 & 32.0 & 4 & 16.0 & \\
\hline Intra oral swelling & 17 & 68.0 & 8 & 32.0 & \\
\hline Intra and extra oral swelling & 0 & 0.0 & 9 & 36.0 & $0.001^{s}$ \\
\hline \multicolumn{6}{|l|}{ Obliteration of the angle of mandible } \\
\hline & 0 & 0.0 & 4 & 16.0 & \\
\hline \multicolumn{6}{|l|}{ After 15 days } \\
\hline None & 21 & 84.0 & 11 & 44.0 & \\
\hline Intra oral swelling & 4 & 16.0 & 6 & 24.0 & \\
\hline Intra and extra oral swelling & 0 & 0.0 & 7 & 28.0 & $0.005^{s}$ \\
\hline Obliteration of the angle of mandible & 0 & 0.0 & 0 & 0.0 & \\
\hline
\end{tabular}

$\mathrm{S}=$ significant, $\mathrm{P}$ value reached from fisher exact test.

Table II shows the swelling of the study patients during 15 days and observed that, after 3 days intra oral swelling was found $13(52.0 \%)$ in group A and $4(16.0 \%)$ in group B patients. After 7 days intra oral swelling was found $17(68.0 \%)$ in group $A$ and $8(31.0 \%)$ in group $B$ patients. After 15 days intra oral swelling was found $4(16.0 \%)$ in group $A$ and $6(24.0 \%)$ in group $B$ patients. The difference was statistically significant $(p<0.05)$ between two groups.

Table III: Distribution of the study patients by pain in postoperative evaluation period $(n=50)$.

\begin{tabular}{|c|c|c|c|c|c|}
\hline \multirow[t]{2}{*}{ Pain (VAS score) } & \multicolumn{2}{|c|}{ Group A ( $n=25)$} & \multicolumn{2}{|c|}{ Group B (n=25) } & \multirow{2}{*}{$P$ value } \\
\hline & $\mathrm{n}$ & $\%$ & $\mathrm{n}$ & $\%$ & \\
\hline \multicolumn{6}{|l|}{ After 3 days } \\
\hline No pain & 0 & 0.0 & 0 & 0.0 & \\
\hline Mild pain & 6 & 24.0 & 1 & 4.0 & \multirow{2}{*}{$0.001^{s}$} \\
\hline Moderate pain & 19 & 76.0 & 14 & 56.0 & \\
\hline \multirow[t]{2}{*}{ Sharp/Spontaneous pain } & & & & & \\
\hline & 0 & 0.0 & 10 & 40.0 & \\
\hline \multicolumn{6}{|l|}{ After 7 days } \\
\hline No pain & 0 & 0.0 & 0 & 0.0 & \\
\hline Mild pain & 19 & 76.0 & 9 & 36.0 & \\
\hline Moderate pain & 6 & 24.0 & 16 & 64.0 & $0.004^{\mathrm{s}}$ \\
\hline \multirow{2}{*}{ Sharp/Spontaneous pain } & & & & & \\
\hline & 0 & 0.0 & 0 & 0.0 & \\
\hline \multicolumn{6}{|l|}{ After 15 days } \\
\hline No pain & 6 & 24.0 & 0 & 0.0 & \\
\hline Mild pain & 19 & 76.0 & 20 & 80.0 & \\
\hline Moderate pain & 0 & 0.0 & 5 & 20.0 & $0.004^{s}$ \\
\hline \multirow[t]{2}{*}{ Sharp/Spontaneous pain } & & & & & \\
\hline & 0 & 0.0 & 0 & 0.0 & \\
\hline
\end{tabular}

$S=$ significant, $P$ value reached from fisher exact test 
According to Visual Analogue Scale (VAS):

\begin{tabular}{lllll}
\hline $\mathbf{0}$ & No pain & $\mathbf{1 - 2}$ & $:$ & Mild pain \\
\hline 3-4 & Tolerable pain & $5-6$ & $:$ & Distressful pain \\
\hline 7-8 & Severer pain & $\mathbf{9 - 1 0}$ & $:$ & Unbearable pain \\
\hline
\end{tabular}

Table III shows the pain status of the study patients during 15 days and observed that, no pain was found in both group at 3 and 7 days. After fifteen days mild pain was found $19(76.0 \%)$ patients in group A and $20(80.0 \%)$ in group B patients. The difference was statistically significant $(p<0.05)$ between twogroups.

\section{DISCUSSION}

This study was carried out in the Oral and Maxillofacial Surgery Department of BSMMU. Fifty patients were selected randomly. Twenty five patients were prescribed Bromelain- Trypsin combination (Treatment group-A) and twenty five patients were prescribed Diclofenac Sodium (Treatment group-B). Among treatment groupA, 25 patients were allocated for Bromelain - Trypsin combination $60 \%$ were male and $40 \%$ were female. Among treatmentgroup-B, $36 \%$ were male and $64 \%$ were female. In this study the mean age difference was not statistically significant $(P>0.05)$ between two groups. No significant difference was found between two groups of patient in respect of sex and chief complaints.

In the result, all groups in this study showed improvement of mouth opening. An association was observed between the groups and periods of normal state. After 3 days mean mouth opening was found $36.0 \pm 8.2 \mathrm{~mm}$ in group A and $31.1 \pm 6.0 \mathrm{~mm}$ in group B. After 7 days mean mouth opening was found $41.4 \pm 7.5$ $\mathrm{mm}$ in group $A$ and $36.7 \pm 6.0 \mathrm{~mm}$ in group $B$. After 15 days mean mouth opening was found $44.6 \pm 11.8 \mathrm{~mm}$ in group $A$ and $41.2 \pm 5.5 \mathrm{~mm}$ in group $B$. The mean mouth opening after 3 and 7 days were statistically significant $(p<0.05)$ between two groups. It suggests that mouth opening was improved in Group-A patients. Study conducted by Maria et al. (2014), in a prospective double blind clinical trial, regarding measurement of the oral aperture it was observed that after day 3 and specifically in the evaluation at the end of treatment on day 8 , there is a tendency to an increased oral aperture $(3 \mathrm{~mm}$ more than the average) in the group receiving Bromelain, although the results were not significant. ${ }^{12}$

In the current study, the result of the study patient by swelling in evaluation period was significant. The comparison among the groups revealed a significant reduction in swelling at $3^{\text {rd }}, 7$ th and $15^{\text {th }}$ days. The swelling of the study patients during 15 days and observed that intra oral swelling was found $13(52.0 \%)$ in group $A$ and $4(16.0 \%)$ in group B after 3 days. Intra oral swelling was found $17(68.0 \%)$ in group $A$ and $8(31.0 \%)$ in group $B$ after 7 days. Intra oral swelling was found $4(16.0 \%)$ in group $A$ and $6(24.0 \%)$ in group B after 15 19| P a g e days. The difference was statistically significant $(p<0.05)$ between two groups. This is in agreement with conclusions of Majid and Mashhadani (2014), who found that Bromelain has analgesic and anti-inflammatory effects comparable to those of preemptive Diclofenac Sodium in the third molar surgery setting. ${ }^{1}$ In 2014, Maria et al, reported the biggest effect of Bromelain in inflammation started from a slightly higher swelling values and at the end of treatment, there was a slight tendency to a reduction in inflammation $(0.65 \pm 0.6$ vs $0.88 \pm 0.8) .^{12}$

Al-Sandook et al. (2014) in a study, a total of 30 patients, into two groups, 15 patients received Orthal-forte tablet and conventional treatment while the control group (15 patients) received conventional treatment. The result was considerable increase in cheek thickness in both groups in the postoperative period appeared when comparison of preoperative and postoperative measurement. The maximum cheek thickness observed in $3^{\text {rd }}$ postoperative day in two groups. The statistical significant reduction in extent cheek swelling in Orthal forte group at $2^{\text {nd }}, 3^{\text {rd }}$ and $7^{\text {th }}$ postoperative day, as compared to control group. ${ }^{13}$

In the current study, the results of the pain levels (VAS) showed that there was significant improvement in the pain scores between all-time intervals with the highest values of improvement from $3\left(p=0.001^{s}\right)$ to $15(p=0$ $.004^{\mathrm{s}}$ ) day postoperative interval. Pain status of the study patients during 15 days and observed that no pain was found in both group at $3^{\text {rd }} \& 7^{\text {th }}$ day. On $15^{\text {th }}$ day mild pain was found $19(76.0 \%)$ cases in group-A and $20(80.0 \%)$ in group-B. The difference was statistically significant $(p<0.05)$ between two groups. This is an agreement with the conclusions of Majid and Mashhadani (2014), who found that Bromelain showed a significant analgesic effect during first postoperative week compared with placebo. ${ }^{1}$ The finding was that Bromelain showed significant positive effect on the QOL measured after third molar removal. This could justify considering Bromelain as an effective alternative to NSAIDs to relieve patient's symptoms and improve their wellbeing during the early post- operative period.

In conclusion perioperative Bromelain - Trypsin combination showed a significant analgesic and anti edemic effect, a significant improvement of mouth opening in the early post-operative period for patients who had under gone lower third molar surgery. This effect was comparabale to that of Diclofenac Sodium in all parameters, making Bromelain-Trypsin a good Website: https://www.banglajol.info/index.php/UpDCJ 
alternative to NSAIDs to provide a more comfortable post-operative course to these patients.

\section{CONCLUSION}

The study concludes that the effectiveness of BromelainTrypsin combination was better than Diclofenac Sodium on postoperative period after surgical removal of mandibular impacted $3^{\text {rd }}$ molar.

\section{REFERENCES}

1. Majid, O. W. B, Mashhadani, A. A. (2014) Perioperative Bromelain Reduces Pain and Swelling and Improves Quality of Life Measures after Mandibular Third Molar Surgery: A Randomized, Double -Blind, PlaceboControlled Clinical Trial, Journal of Oral Maxillofacial Surgery, 72, pp. 1043-1048.

https://doi.org/10.1016/j.joms.2013.12.035

PMid:24589242

2. Copper, S. A, Beaver, W. T. (1976) A model to evaluate mild analgesics in oral surgery out patients, Journal of Clinical Pharmacology and Therapeutics, 2 , https://doi.org/10.1002/cpt1976202241

PMid:780041

3. Seymour, R.A, Walton, J.G, (1984) Pain control after third molar surgery, International Journal of Oral Surgery, 13(6), pp. 457-485. https://doi.org/10.1016/S0300-9785(84)80017-4

4. Little, J. W, Falace, D. A, Miller, C.S, Rhodus, N.L.(1997) Dental Management of the Medically Compromised Patient (ed5). St. Louis, MO, Mosby.

5. McGrath, C, Comfort, M. B, Lo E. C. M, Luo,Y. (2003) Changes in life quality following third molar surgery-the immediate postoperative period, British Dental Journal, 194, pp. 265-268. https://doi.org/10.1038/sj.bdj.4809930

\section{PMid:12658303}

6. Oginni, F, Ugboko, V. I, Assam, E, Ogunboded, E. O. (2002) Postoperative complaints following impacted mandibular third molar surgery in lle-lfe, Nigeria, Journal of the South African Dental Association, 57(7), pp. 264268.

7. Kirtiloglu T. B. E, Summer, M.G.I.(2007)Comparison of 2 flap designs in the periodontal healing of second molar after fully impacted mandibular third molar extraction, Journal of Oral Maxillofacial Surgery, 65, pp. 2206-2210.

https://doi.org/10.1016/j.joms.2006.11.029

PMid:17954315

8. Barone, A, Marconcini, S, Giacomelli, L, Rispoli, L, Calvo, J. L, Covani U.(2010)'A randomized clinical evaluation of ultrasound bone surgery verses traditional rotary instruments in lower third molar extraction', Journal of Oral and Maxillofacial Surgery, 68 (2), pp. 330-336. https://doi.org/10.1016/j.joms.2009.03.053 PMid:20116704

9. Sierra, R. A, Molina, D. E, Autos, N. L, Escoda, G.C.(2007)Comparative study of the anesthetic efficiency of $4 \%$ articaine versus $2 \%$ lidocaine in inferior alveolar nerve block during surgical extraction of impacted lower third molar, Journal of Medicina Oral Patologia Oral Y Cirugia Bucal, 12, pp. 139-144.

10. Kaur, R, Abmwani, S, Mehta, B. (2014) Trypsin, Rutoside and Bromelain alone and fixed dose combination: A natural, safer and effective antiinflammatory agent, Journal of Drug Delivery \& Therapeutics, 4(1), pp.108-110. https://doi.org/10.22270/jddt.v4i1.746

11. Robinson, M. (2012) Non-steriodal antiinflammatory drugs (NSAIDs), Further evidence that the cardiovascular risk with diclofenac is higher than the other non-selective NSAIDs and similar to the selective COX-2 inhibitors, Journal of Drug Safety Update, 6 (3), pp. 36-39.
12. Maria, C. B, Rosa-Maria, Y. V, Batista - Cruzado, A. J, M. H, Castillo-de, R. O, Torres- Lagares, D. (2014) Prospective double -blind clinical trial evaluating the effectiveness of Bromelain in the third molar extraction postoperative period, Journal of Medicine Oral Patologia Oral Y Cirugia Bucal.19(2),

pp. https://doi.org/10.4317/medoral.19105 PMid:24316697 PMCid:PMC4015046

13. Al - Sandook, T. A. A, Tawfik, N.O.M, Qassim, D. A. (2014) Clinical evaluation of the efficacy of orthal- forte (prolytic enzymes, trypsin and chymotrypsin) on postoperative sequel following the removal of lower impacted third molar, International journal of Enhanced Research in Science Technology \& Engineering, 3 (2), pp. 169-173. 